BMJ Open

Sport \&

Exercise

Medicine

\title{
Association between frontal plane knee control and lower extremity injuries: a prospective study on young team sport athletes
}

Anu M Räisänen, ${ }^{1}$ Kati Pasanen, ${ }^{2,3}$ Tron Krosshaug, ${ }^{4}$ Tommi Vasankari, ${ }^{3}$ Pekka Kannus, ${ }^{3}$ Ari Heinonen, ${ }^{5}$ Urho M Kujala, ${ }^{5}$ Janne Avela, ${ }^{5}$ Jarmo Perttunen, ${ }^{6}$ Jari Parkkari ${ }^{1}$

To cite: Räisänen AM, Pasanen $\mathrm{K}$, Krosshaug $\mathrm{T}$, et al. Association between frontal plane knee control and lower extremity injuries: a prospective study on young team sport athletes. BMJ Open Sport \& Exercise Medicine 2018;4:e00311. doi:10.1136/ bmjsem-2017-000311

Received 18 October 2017 Revised 9 December 2017 Accepted 14 December 2017

\section{(a) CrossMark}

${ }^{1}$ Tampere Research Center of Sports Medicine, UKK Institute for Health Promotion Research, Tampere, Finland

${ }^{2}$ Sport Injury Prevention Research Centre, Faculty of Kinesiology, University of Calgary, Calgary, Alberta, Canada

${ }^{3}$ UKK Institute for Health Promotion Research, Tampere, Finland

${ }^{4}$ Norwegian School of Sports Sciences, 0slo Sports Trauma Research Center, Oslo, Norway ${ }^{5}$ Faculty of Sport and Health Sciences, University of Jyväskylä, Jyväskylä, Finland ${ }^{6}$ Tampere University of Applied Sciences, Tampere, Finland

Correspondence to

Anu M Räisänen; anu.raisanen@ uta.fi

\section{ABSTRACT}

Background/aim Poor frontal plane knee control can manifest as increased dynamic knee valgus during athletic tasks. The purpose of this study was to investigate the association between frontal plane knee control and the risk of acute lower extremity injuries. In addition, we wanted to study if the single-leg squat (SLS) test can be used as a screening tool to identify athletes with an increased injury risk.

Methods A total of 306 basketball and floorball players participated in the baseline SLS test and a 12-month injury registration follow-up. Acute lower extremity time-loss injuries were registered. Frontal plane knee projection angles (FPKPA) during the SLS were calculated using a two-dimensional video analysis.

Results Athletes displaying a high FPKPA were 2.7 times more likely to sustain a lower extremity injury (adjusted OR 2.67, $95 \% \mathrm{Cl} 1.23$ to 5.83 ) and 2.4 times more likely to sustain an ankle injury (OR $2.37,95 \% \mathrm{Cl} 1.13$ to 4.98 ). There was no statistically significant association between FPKPA and knee injury (OR 1.49, 95\% $\mathrm{Cl} 0.56$ to 3.98$)$. The receiver operating characteristic curve analyses indicated poor combined sensitivity and specificity when FPKPA was used as a screening test for lower extremity injuries (area under the curve of 0.59 ) and ankle injuries (area under the curve of 0.58 ).

Conclusions Athletes displaying a large FPKPA in the SLS test had an elevated risk of acute lower extremity and ankle injuries. However, the SLS test is not sensitive and specific enough to be used as a screening tool for future injury risk.

\section{INTRODUCTION}

In fast-paced team sports such as football, basketball, handball and floorball, injury incidence is high and adolescents are injured more frequently than children or adults. ${ }^{1-6}$ In these sports, most injuries occur in the lower extremities. ${ }^{1-5} 7$ To reduce the burden of sports injuries, it is essential to identify modifiable risk factors, which can be targeted with injury prevention strategies. Neuromuscular deficiencies, such as poor frontal plane

\section{What are the new findings?}

- Previously healthy athletes, who displayed large frontal plane knee projection angles during the single-leg squat (SLS) test, were 2.7 times more likely to sustain acute lower extremity injuries.

- Large frontal plane knee projection angles were most clearly associated with acute ankle injuries.

- Measuring the frontal plane knee projection angles in the SLS test is not sensitive and specific enough to be used as a screening tool.

knee control, are potentially modifiable intrinsic factors and possibly associated with a higher risk of lower extremity injury. ${ }^{89}$ Inadequate ability to control knee movement on the frontal plane can manifest as high knee valgus.

To our knowledge, there are no previous studies investigating the association between frontal plane knee projection angle (FPKPA) and lower extremity injuries. Some previous studies have examined the associations between other measurements of knee control and lower extremity injuries. Hewett et al demonstrated that among female high school athletes, athletes suffering an anterior cruciate ligament injury during the follow-up demonstrated 2.5 times greater knee abduction moment during a baseline vertical drop jump than athletes who remained uninjured. ${ }^{10}$ However, this finding was not supported by studies on adult female football and handball players and young female floorball and basketball players. ${ }^{11}{ }^{12}$ In young female football players, low normalised knee separation in the vertical drop jump test was associated with a higher risk of acute lower extremity injuries. ${ }^{13}$ The previous studies on knee control are not in agreement but they indicate that the role of knee control on injury risk should be investigated 
further. The single-leg squat (SLS) is a movement control test often used in clinical practice and research to assess frontal plane knee control, but it has not been previously studied as a potential screening test. ${ }^{14-18}$

Two-dimensional (2D) video analysis of the SLS is a reliable tool to measure knee valgus, and it has been validated against the gold standard, three-dimensional (3D) motion analysis. ${ }^{1920}$ Whereas the $3 \mathrm{D}$ analysis is usually costly and performed in a laboratory environment, the 2D method is easy to set up in a field setting. This ease of use, coupled with the lower cost of the analysis, makes the
2D method more feasible for large-scale screenings and was therefore chosen.

The objective of this study was to investigate the association between FPKPA and acute lower extremity injuries in young, previously healthy athletes. In addition to lower extremity injuries, we wanted to explore the association between FPKPA and ankle injuries and knee injuries specifically, as these are the most commonly injured body parts in team sports. Furthermore, we set out to investigate if the SLS test is a suitable screening tool to identify athletes with increased risk of injury.

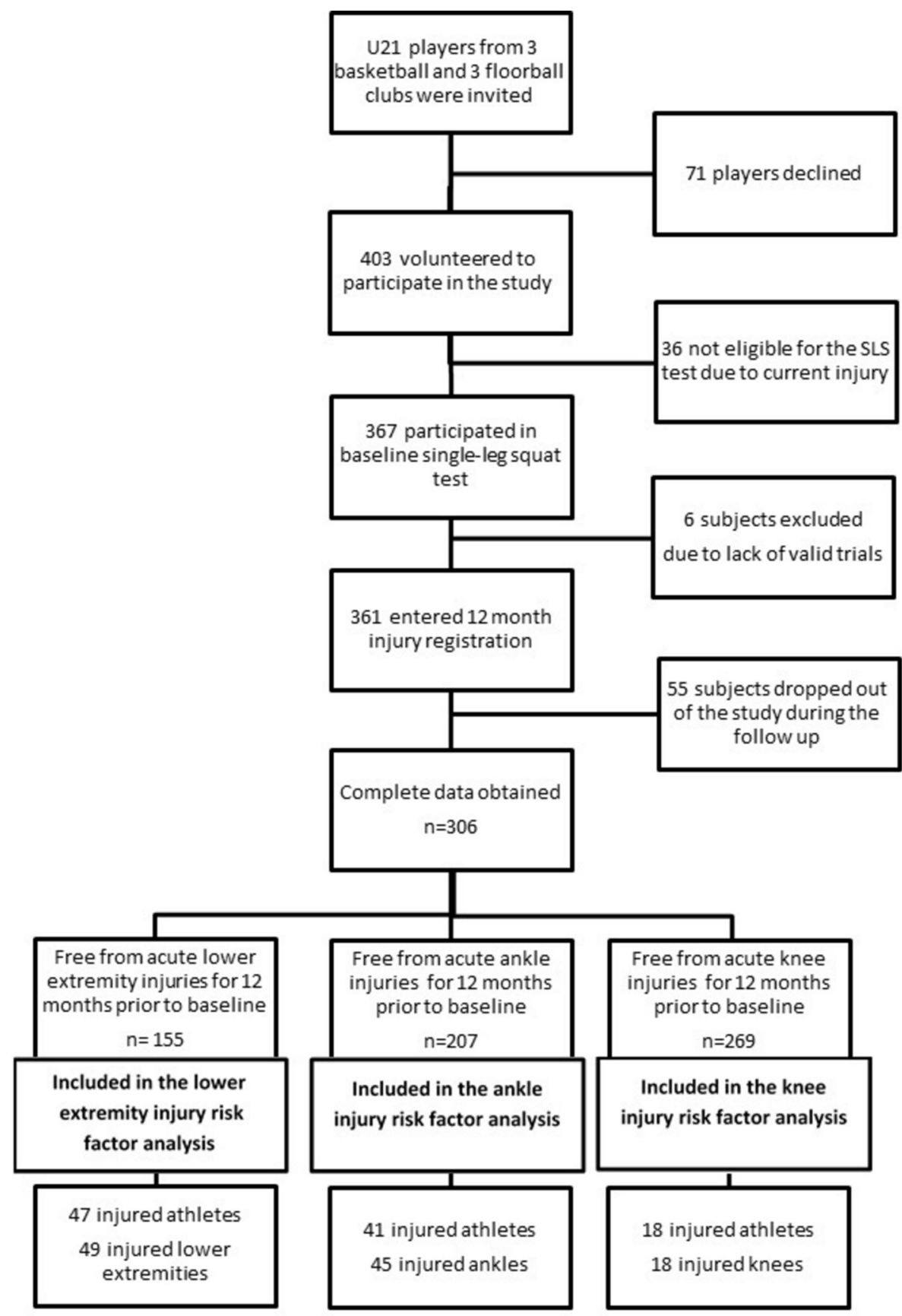

Figure 1 Number of athletes included in the analysis of lower extremity injury risk, ankle injury risk and knee injury risk. Athletes sustaining knee and ankle injuries were also included in the analysis of all lower extremity injuries. SLS, single-leg squat. 


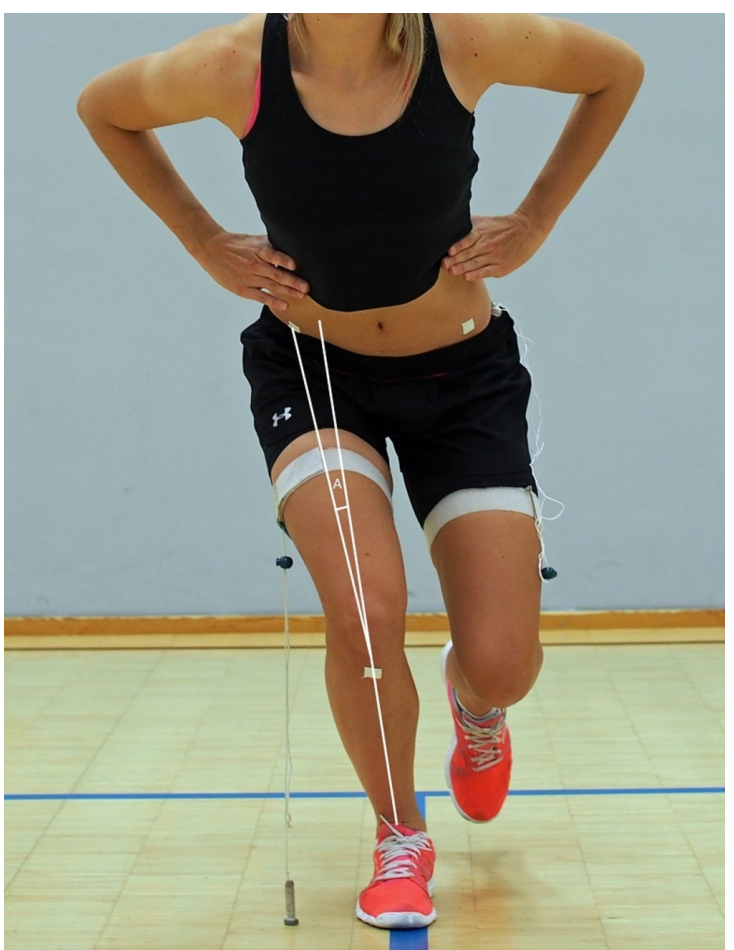

Figure 2 An athlete demonstrating the single-leg squat test. ' $A$ ' marks the frontal plane knee projection angle.

\section{MATERIALS AND METHODS}

\section{Study design and participants}

This study is part of a prospective cohort study (the PROFITS study) and the protocol has been published elsewhere. ${ }^{21}$ Subjects were young basketball and floorball players aged 21 years and under. The data set comprised their personal details (sex, height, weight, exposure, sport played, etc), baseline SLS test results and prospective 1-year injury data. The number of subjects at each stage is presented in figure 1.

Subjects free of lower extremity injury participated in the baseline measurements. A total of 367 athletes participated in the SLS test. Of this number, six athletes were excluded since they did not perform enough valid trials. Subjects provided written informed consent. For subjects younger than 18 years, consent was also sought from a legal guardian.

\section{Baseline measurements}

Athletes entered the study during the preseason of 2011, 2012 or 2013. Athletes' height and weight were measured, and body mass index (BMI, $\left.\mathrm{kg} / \mathrm{m}^{2}\right)$ was calculated. Athletes filled out a questionnaire on the time-loss injuries they had sustained during the past 12 months.

The SLS test was based on the work of Stensrud et al, and the detailed test protocol has been published previously. ${ }^{172122}$ Subjects performed three SLS to $90^{\circ}$ knee flexion on each leg. Trials were recorded with a high-definition digital video camera (HXR-NX70E, Sony Japan). The mean FPKPA for each leg from a minimum of two valid squats was calculated from the video footage by the primary investigator (AMR) using a Java-based computer software (ImageJ, National Institutes of Health). The squat was deemed invalid if the non-weight-bearing leg was held in the front or to the side or it touched the floor or if the player fell, looked down or moved their hands from the waist. The video analysis was conducted blind to past and future injury status. The FPKPA was calculated as the intersection of a line created by the anterior superior iliac spine and knee joint centre and the line created by the knee joint centre and the ankle joint centre. Neutral alignment was considered $0^{\circ}$, positive values represented valgus alignment and negative values represented varus alignment. The measurement of FPKPA is presented in figure 2. The video analysis method has been described in detail previously. ${ }^{22}$

\section{Injury definition, and injury and exposure registration}

'Injury' was defined as any acute lower extremity (hip, groin, thigh, knee, lower leg, ankle, foot) injury that resulted in an athlete being unable to fully participate in training or match play for at least 24 hours. The injuries were recorded by a team coach or another designated team member. For injury registration, the study physicians and study assistants contacted the teams on a weekly basis. The study physicians contacted the athlete after each injury and collected information about the injury time, place, cause, type, location and the time-loss due to the injury in a standardised phone interview. For exposure registration, the team coaches recorded athlete participation in team practice and match play. After each follow-up month, the coach emailed the participation records to the study group.

\section{Statistical methods}

Injury risk does not necessarily increase or decrease linearly; therefore, categorical variables were used in addition to continuous variables. ${ }^{23}$ To account for the possibly non-linear association between a variable and injury risk, continuous variables were transformed into categorical variables using the mean averages and SD of the entire cohort. ${ }^{23}$ Age, height, weight, BMI, FPKPA, training exposure, match exposure and total exposure were each categorised into three groups: the intermediate reference group (mean $\pm 1 \mathrm{SD})$, the low group (values lower than $1 \mathrm{SD}$ below the mean) and the high group (values higher than $1 \mathrm{SD}$ above the mean).

Analyses were performed using SPSS (V.23, SPSS). To compare the athletes injured during the follow-up with the uninjured athletes, the Mann-Whitney $\mathrm{U}$ test was used to test the variables that were not normally distributed (age, BMI, exposure variables), the independent samples $t$ test was used for the normally distributed variables (height, weight, FPKPAs) and the $\chi^{2}$ test was used for the categorical variables (sex, sport).

A generalised linear mixed model for binary data with injury/no injury as the dependent variable was used to analyse the potential risk factors. The generalised linear mixed model was chosen as it allows the use of random effects. Team and leg were used as random 
effects. The analyses were performed using each leg as a unit of analysis. To ensure the equal length of exposure period, only athletes who completed the 12-month follow-up were analysed. Only athletes free from lower extremity injuries during the previous year were included in the lower extremity injury risk factor analysis. Similarly, only athletes without ankle or knee injuries were included in the ankle and knee injury risk factor analyses, respectively. The number of athletes included in each analysis is presented in figure 1. ORs, derived from the univariate and multivariate analysis, quantify the association between the factor and the occurrence of injury. First, the baseline risk factors were analysed using the univariate model. All the variables with a $P$ value $<0.20$ in the univariate analysis were entered into a multivariate model to generate the adjusted ORs. In the multivariate analysis, the significance level was set at $\mathrm{P}<0.05$. Receiver operating characteristic (ROC) curve analyses were performed to analyse the sensitivity and the specificity of the identified risk factors. Area under the curve (AUC) was used to classify the combined sensitivity and specificity as outstanding (0.90-1), excellent $(0.80-0.89)$, acceptable $(0.70-0.79)$, poor $(0.51-0.69)$ and no discrimination $(0.50) .^{24}$

\section{RESULTS}

\section{Subjects}

Complete data were obtained from 306 athletes (age $15.7 \pm 1.8$ years, height $173.3 \pm 9.1 \mathrm{~cm}$, weight $64.6 \pm 10.0 \mathrm{~kg}$ ), of which $52 \%$ were male. The proportions of basketball and floorball players were equal. The mean FPKPA was $13.3^{\circ} \pm 10.5^{\circ}$.

Of the 306 subjects, 155 were free from acute lower extremity (hip, groin, thigh, knee, lower leg, ankle, foot) injury, 207 athletes were free from acute ankle injuries and 269 were free from acute knee injuries for 12 months before entering the study. The 110 injured athletes did not differ from the 196 uninjured athletes by age, height, weight, BMI, gender, sport, training exposure, match exposure or match and training exposure. Athletes sustaining ankle or knee injuries were also analysed in the analysis of all acute lower extremity injuries. The number of athletes at each stage of the study is presented in figure 1.

\section{Risk factors for acute lower extremity injuries}

During the 12-month follow-up, 47 of the 155 athletes sustained acute lower extremity injuries. Two athletes had sustained injuries to both legs during the follow-up. In the multivariate model, only a FPKPA greater than 1 SD above the mean $\left(>23.8^{\circ}\right)$ was associated with lower extremity injuries (adjusted OR 2.67, 95\% CI 1.23 to 5.83). The ORs from the univariate analysis and the adjusted ORs from the multivariate analysis are presented in table 1.

\section{Risk factors for acute ankle injuries}

Of the 207 athletes, 41 suffered acute ankle injuries during the follow-up. Four athletes injured both ankles.
Displaying a FPKPA greater than 1 SD above the mean $\left(>23.8^{\circ}\right)$ in the SLS test was associated with a higher risk of ankle injury (OR 2.37, 95\% CI 1.13 to 4.98 ). Since none of the other variables achieved $\mathrm{P}<0.20$ in the univariate analysis, no multivariate analysis was performed. The ORs for the variables in the univariate analysis are presented in table 2.

\section{Risk factors for acute knee injuries}

During the follow-up, 18 knee injuries were recorded for the 269 athletes. No statistically significant associations between the analysed variables and knee injuries were detected. The OR for displaying a FPKPA greater than $1 \mathrm{SD}$ above the mean $\left(>23.8^{\circ}\right)$ in the SLS test was 1.49 (95\% CI 0.56 to 3.98 ), but this was not statistically significant. Since only the categorical variable of age achieved $\mathrm{P}<0.20$ in the univariate analysis, no multivariate analysis was performed. The ORs for the variables in the univariate analysis are presented in table 3 .

\section{Specificity and sensitivity analyses}

The ROC curve analysis for the FPKPA and lower extremity injuries showed an AUC of 0.59, which indicates poor specificity and sensitivity. For the FPKPA and ankle injuries, the AUC was 0.58, indicating poor specificity and sensitivity. The distribution of the injured and uninjured lower extremities by FPKPA is presented in figure 3. The figure illustrates that there is substantial overlap between the injured and uninjured athletes.

\section{DISCUSSION \\ FPKPA and injury risk}

This study focused on a previously established knowledge gap in the association between the results of a functional movement control test and the risk of lower extremity injury. Our results demonstrate that excessive knee valgus motion during the SLS is associated with lower extremity injuries: athletes displaying a large FPKPA were 2.7 times more likely to sustain a lower extremity injury compared with the athletes displaying intermediate values.

To our knowledge, there are no previous studies examining the association between FPKPA and lower extremity injury risk. Previous studies have hypothesised that knee valgus motion during the SLS test could be related to injury risk and have acknowledged the need to study this association. ${ }^{162025}$ A previous study has linked knee valgus motion during the vertical drop jump test to an increased risk of ACL injuries in adolescents female athletes, but this finding has not been confirmed in later studies. ${ }^{10-12}$ In this study, none of the variables were associated with the risk of knee injuries. However, the small number of injured knees $(n=18)$ could have a considerable influence on why no potential risk factors were identified.

\section{Knee control is a modifiable risk factor}

Due to the multifactorial nature of sports injuries, athletes with good knee control do also sustain injuries. However, athletes with poor knee control would 
Table 1 ORs for potential lower extremity injury risk factors among young athletes

\begin{tabular}{|c|c|c|c|}
\hline & OR & $95 \% \mathrm{Cl}$ & $P$ value \\
\hline \multicolumn{4}{|l|}{ Univariate analysis } \\
\hline \multicolumn{4}{|l|}{ Categorical variables } \\
\hline Basketball & 1 & & \\
\hline Floorball & 0.97 & 0.52 to 1.79 & 0.92 \\
\hline Female & 1 & & \\
\hline Male & 1.08 & 0.58 to 1.99 & 0.81 \\
\hline $\begin{array}{l}\text { Age, intermediate } \\
(\text { mean } \pm S D)\end{array}$ & 1 & & \\
\hline $\begin{array}{l}\text { Age, low ( }<1 \mathrm{SD} \text { below } \\
\text { mean, }<13.9 \text { years) }\end{array}$ & 1.58 & 0.72 to 3.50 & 0.26 \\
\hline $\begin{array}{l}\text { Age, high ( }>1 \mathrm{SD} \text { above } \\
\text { mean, }>17.5 \text { years) }\end{array}$ & 1.35 & 0.55 to 3.35 & 0.51 \\
\hline $\begin{array}{l}\text { Height, intermediate } \\
\text { (mean } \pm S D)\end{array}$ & 1 & & \\
\hline $\begin{array}{l}\text { Height, low }(<1 \mathrm{SD} \text { below } \\
\text { mean, }<164.2 \mathrm{~cm})\end{array}$ & 0.81 & 0.35 to 1.87 & 0.62 \\
\hline $\begin{array}{l}\text { Height, high (>1SD } \\
\text { above mean,>182.4 cm) }\end{array}$ & 0.91 & 0.37 to 2.22 & 0.83 \\
\hline $\begin{array}{l}\text { Weight, intermediate } \\
\text { (mean } \pm \text { SD) }\end{array}$ & 1 & & \\
\hline $\begin{array}{l}\text { Weight, low }(<1 \text { SD below } \\
\text { mean, }<54.7 \mathrm{~kg})\end{array}$ & 0.71 & 0.28 to 1.79 & 0.46 \\
\hline $\begin{array}{l}\text { Weight, high (>1SD } \\
\text { above mean,>74.6 kg) }\end{array}$ & 0.51 & 0.17 to 1.50 & 0.22 \\
\hline $\begin{array}{l}\text { BMI, intermediate } \\
\text { (mean } \pm \text { SD) }\end{array}$ & 1 & & \\
\hline $\begin{array}{l}\text { BMI, low }(<1 \text { SD below } \\
\text { mean, }<19.0)\end{array}$ & 0.99 & 0.42 to 2.30 & 0.97 \\
\hline
\end{tabular}

BMI, high (>1SD above

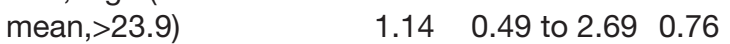

FPKPA, intermediate

(mean \pm SD)

FPKPA, low $(<1$ SD below

mean, $\left.<2.7^{\circ}\right) \quad 1.12 \quad 0.43$ to $2.90 \quad 0.82$

FPKPA, high $(>1 \mathrm{SD}$

above mean, $\left.>23.8^{\circ}\right) \quad 2.551 .18$ to $5.51 \quad 0.02^{*}$

Training exposure,

intermediate $\left(\right.$ mean $\left._{ \pm} \mathrm{SD}\right) \quad 1$

Training exposure,

low ( $<1 \mathrm{SD}$ below

mean, $<162.4$ hours) $\quad 1.33 \quad 0.58$ to 3.020 .50

Training exposure.

high $(>1 \mathrm{SD}$ above

mean,>346.0 hours) $\quad 0.83 \quad 0.30$ to 2.280 .71

Match exposure,

intermediate $($ mean \pm SD) 1

Match exposure,

low $(<1 \mathrm{SD}$ below

mean, $<3.9$ hours)
Table 1 Continued

OR $\quad 95 \% \mathrm{Cl} \quad$ P value

Match exposure,

high ( $>1$ SD above

mean, $>15$ hours)

0.690 .29 to 1.650 .41

Match and training

exposure, intermediate

(mean \pm SD)

1

Match and training

exposure, low

$(<1 \mathrm{SD}$ below

mean, $<169.6$ hours) $\quad 1.190 .51$ to 2.780 .70

Match and training

exposure. high

$(>1 \mathrm{SD}$ above

mean, $>357.7$ hours) $\quad 0.81 \quad 0.29$ to 2.230 .68

Continuous variables

$\begin{array}{lll}\text { Age (years) } & 1.04 & 0.87 \text { to } 1.24 \quad 0.67\end{array}$

Height $(\mathrm{cm}) \quad 1.00 \quad 0.97$ to 1.040 .85

$\begin{array}{lll}\text { Weight }(\mathrm{kg}) & 1.00 & 0.97 \text { to } 1.040 .86\end{array}$

BMI (kg/m²) $\quad 1.010 .90$ to 1.140 .87

FPKPA $\left(^{\circ}\right) \quad 1.010 .98$ to 1.050 .38

Training exposure (hour) $1.00 \quad 1.00$ to $1.00 \quad 0.95$

Match exposure (hour) $\quad 0.99 \quad 0.94$ to 1.050 .82

Match and training

exposure (hour)

1.001 .00 to 1.000 .94

Multivariate analysis

FPKPA $>1$ SD above mean

$(>23.8)$

2.671 .23 to $5.83 \quad 0.01 \dagger$

All variables are presented for the univariate analysis, but only variables with a $P$ value $<0.05$ are presented for the multivariate analysis.

*Variables achieving $\mathrm{P}<0.20$ in the univariate analysis were entered into the multivariate model.

†Only variables achieving $\mathrm{P}<0.05$ in the multivariate model are presented.

$\mathrm{BMI}$, body mass index; FPKPA, frontal plane knee projection angle.

benefit most from neuromuscular training planned to improve knee control. ${ }^{26}$ In previous studies, poor frontal plane knee control has been associated with reduced hip muscle strength. ${ }^{25} 27$ Hip abduction strength and hip external rotation strength, in particular, are valuable predictors of frontal plane knee control. ${ }^{25} 2728$ Crossley et al demonstrated that for every $1 \%$ improvement in hip abduction strength normalised to body weight, the FPKPA would improve by $0.2^{\circ} .{ }^{14}$ In addition, knee valgus can be a consequence of delayed activity or a lack of coactivation. ${ }^{14}{ }^{15}$ Delayed gluteus medius activation was measured in subjects who performed poorly in the SLS compared with those who performed well. ${ }^{14}$ Mauntel et al suggested that knee valgus motion is an issue of muscular coactivation. ${ }^{15}$ They reported that subjects displaying valgus motion during the SLS had smaller coactivation ratios of the gluteus medius to hip 
Table 2 ORs for potential ankle injury risk factors

\begin{tabular}{llll}
\hline Univariate analysis & OR & $\mathbf{9 5 \%} \mathbf{C l}$ & P value \\
\hline $\begin{array}{l}\text { Categorical variables } \\
\text { Basketball }\end{array}$ & 1 & & \\
\hline Floorball & 0.72 & 0.39 to 1.34 & 0.29 \\
\hline Female & 1 & & \\
\hline Male & 0.84 & 0.45 to 1.55 & 0.58 \\
\hline
\end{tabular}

Age, intermediate

(mean \pm SD)

Age, low $(<1 \mathrm{SD}$ below

mean, $<13.9$ years)

0.87

Age, high ( $>1$ SD above

mean, $>17.5$ years)

$0.92 \quad 0.37$ to $2.29 \quad 0.85$

Height, intermediate (mean \pm SD)

1

Height, low $(<1$ SD below

mean, $<164.2 \mathrm{~cm})$

$1.03 \quad 0.46$ to 2.26

$\begin{array}{lll}\text { Height, high ( }>1 \mathrm{SD} \text { above } & & 0.83 \\ \text { mean, }>182.4 \mathrm{~cm}) & 0.91 & 0.38 \text { to } 2.16^{-}\end{array}$

Weight, intermediate

(mean \pm SD)

1

Weight, low $(<1$ SD below

mean, $<54.7 \mathrm{~kg}$ )

$0.82 \quad 0.31$ to $2.20 \quad 0.70$

Weight, high (>1 SD above

mean, $>74.6 \mathrm{~kg}$ )

$0.94 \quad 0.40$ to $2.23 \quad 0.89$

$\mathrm{BMI}$, intermediate

$($ mean \pm SD)

1

BMI, low $(<1$ SD below

mean, $<19.0)$

$0.80 \quad 0.32$ to $1.98 \quad 0.63$

BMI, high ( $>1$ SD above

mean, >23.9)

$0.93 \quad 0.39$ to $2.21 \quad 0.87$

FPKPA, intermediate

$($ mean \pm SD)

1

FPKPA, low ( $<1$ SD below

mean, $\left.<2.7^{\circ}\right)$

$1.18 \quad 0.46$ to $2.98 \quad 0.73$

FPKPA, high ( $>1$ SD above

mean, $>23.8^{\circ}$ )

2.371 .13 to $4.98 \quad 0.02^{*}$

Training exposure, intermediate $($ mean $\mathrm{SD}) \quad 1$

Training exposure,

low ( $<1 \mathrm{SD}$ below

mean, $<162.4$ hours)

$1.14 \quad 0.50$ to $2.60 \quad 0.76$

Training exposure.

high ( $>1 \mathrm{SD}$ above

mean, $>346$. 0 hours)

$0.71 \quad 0.25$ to $2.03 \quad 0.52$

Match exposure, intermediate $($ mean $\pm \mathrm{SD}) \quad 1$

Match exposure,

low $(<1 \mathrm{SD}$ below

mean, $<3.9$ hours)

Match exposure,

high ( $>1 \mathrm{SD}$ above

mean, $>15$ hours)
Table 2 Continued

\begin{tabular}{|c|c|c|c|}
\hline Univariate analysis & OR & $95 \% \mathrm{Cl}$ & $P$ value \\
\hline $\begin{array}{l}\text { Match and training } \\
\text { exposure, intermediate } \\
\text { (mean } \pm \text { SD) }\end{array}$ & 1 & & \\
\hline $\begin{array}{l}\text { Match and training } \\
\text { exposure, low ( }<1 \text { SD } \\
\text { below mean, }<169.6 \text { hours) }\end{array}$ & 1.02 & 0.43 to 2.42 & 0.96 \\
\hline $\begin{array}{l}\text { Match and training } \\
\text { exposure. high ( }>1 \mathrm{SD} \\
\text { above mean, }>357.7 \text { hours) }\end{array}$ & 0.84 & 0.31 to 2.23 & 0.72 \\
\hline \multicolumn{4}{|l|}{ Continuous variables } \\
\hline Age (years) & 1.00 & 0.84 to 1.20 & 0.97 \\
\hline Height (cm) & 0.99 & 0.96 to 1.03 & 0.65 \\
\hline Weight (kg) & 0.99 & 0.96 to 1.03 & 0.65 \\
\hline $\mathrm{BMI}\left(\mathrm{kg} / \mathrm{m}^{2}\right)$ & 0.99 & 0.87 to 1.12 & 0.85 \\
\hline FPKPA $\left({ }^{\circ}\right)$ & 1.02 & 0.99 to 1.05 & 0.24 \\
\hline Training exposure (hour) & 1.00 & 1.00 to 1.00 & 0.87 \\
\hline Match exposure (hour) & 1.01 & 0.96 to 1.06 & 0.79 \\
\hline $\begin{array}{l}\text { Match and training } \\
\text { exposure (hour) }\end{array}$ & 1.00 & 1.00 to 1.00 & 0.86 \\
\hline
\end{tabular}

Since only one variable achieved $\mathrm{P}<0.20$ were identified in the univariate analysis, no multivariate analysis was performed.

${ }^{*} \mathrm{P}<0.05$.

$\mathrm{BMI}$, body mass index; FPKPA, frontal plane knee projection angle.

adductor and the gluteus maximus to hip adductor, suggesting that subjects displaying knee valgus used a hip adductor-dominant strategy. These neuromuscular factors contributing to frontal plane knee control can be targeted with training.

Since previous research indicates that athletes are able to improve their knee control through training, neuromuscular training programmes should be used to improve knee control. ${ }^{26} 29-34$ Previously, the effects of neuromuscular training have been measured using the vertical drop jump test. ${ }^{34}$ Using the visual assessment of frontal plane knee control, the SLS and vertical drop jump identified different subjects and approximately $20 \%$ of the subjects displaying reduced knee control would not have been identified using only one of the two tests. ${ }^{17}$ The SLS test could be used in addition to the vertical drop jump test to quantify the effects of neuromuscular training. However, this should be studied in future research.

Several studies have shown that the incidence of lower extremity injuries among adolescent athletes can be reduced by neuromuscular injury prevention programmes. ${ }^{35-45}$ In a recent meta-analysis, Hübscher et al reported that multi-intervention training programmes reduced the risk of lower extremity injuries by $39 \%$, the risk of acute knee injuries by $54 \%$ and the risk of ankle sprains by $50 \% .{ }^{38}$ However, lack of intervention programme uptake in sports is a concern. ${ }^{36}$ Currently, little is known about how much of the reduction in injury 
Table 3 ORs for potential knee injury risk factors

\begin{tabular}{llll}
\hline Univariate analysis & OR & $\mathbf{9 5 \%} \mathbf{C l}$ & P value \\
\hline $\begin{array}{l}\text { Categorical variables } \\
\text { Basketball }\end{array}$ & 1 & & \\
Floorball & 1.53 & 0.69 to 3.41 & 0.30 \\
Female & 1 & & \\
Male & 0.69 & 0.31 to 1.52 & 0.36
\end{tabular}

Age, intermediate

$($ mean \pm SD)

1

$\begin{array}{lll}\text { Age, low }(<1 \mathrm{SD} \text { below } & & \\ \text { mean, }<13.9 \text { years }) & 1.36 & 0.43 \text { to } 4.26\end{array}$

Age, high ( $>1 \mathrm{SD}$ above

mean,>17.5years) $\quad 2.220 .89$ to $5.530 .09^{*}$

\begin{tabular}{llll}
$\begin{array}{l}\text { Height, intermediate } \\
\text { (mean } \pm \text { SD) }\end{array}$ & 1 & & \\
$\begin{array}{l}\text { Height, low }(<1 \mathrm{SD} \text { below } \\
\text { mean, }<164.2 \mathrm{~cm})\end{array}$ & 1.17 & 0.42 to 3.28 & 0.76 \\
$\begin{array}{l}\text { Height, high }(>1 \mathrm{SD} \text { above } \\
\text { mean, }>182.4 \mathrm{~cm})\end{array}$ & 0.81 & 0.27 to 2.50 & 0.72 \\
\hline
\end{tabular}

Weight, intermediate (mean \pm SD)

1

\begin{tabular}{|c|c|c|c|}
\hline $\begin{array}{l}\text { Weight, low }(<1 \text { SD below } \\
\text { mean, }<54.7 \mathrm{~kg})\end{array}$ & 0.88 & 0.26 to 3.03 & 0.85 \\
\hline $\begin{array}{l}\text { Weight, high ( }>1 \text { SD above } \\
\text { mean, }>74.6 \mathrm{~kg})\end{array}$ & 0.77 & 0.25 to 2.31 & 0.64 \\
\hline $\begin{array}{l}\text { BMI, intermediate } \\
(\text { mean } \pm S D)\end{array}$ & 1 & & \\
\hline $\begin{array}{l}\text { BMI, low (<1 SD below } \\
\text { mean, <19.0) }\end{array}$ & 0.92 & 0.27 to 3.09 & 0.89 \\
\hline $\begin{array}{l}\text { BMI, high (>1SD above } \\
\text { mean,>23.9) }\end{array}$ & 1.14 & 0.42 to 3.12 & 0.80 \\
\hline $\begin{array}{l}\text { FPKPA, intermediate } \\
(\text { mean } \pm S D)\end{array}$ & 1 & & \\
\hline $\begin{array}{l}\text { FPKPA, low }(<1 \text { SD below } \\
\left.\text { mean, }<2.7^{\circ}\right)\end{array}$ & 0.76 & 0.20 to 2.82 & 0.68 \\
\hline $\begin{array}{l}\text { FPKPA, high ( }>1 \text { SD above } \\
\left.\text { mean, }>23.8^{\circ}\right)\end{array}$ & 1.49 & 0.56 to 3.98 & 0.42 \\
\hline $\begin{array}{l}\text { Training exposure, } \\
\text { intermediate (mean } \pm S D)\end{array}$ & 1 & & \\
\hline $\begin{array}{l}\text { Training exposure, } \\
\text { low (<1SD below } \\
\text { mean, }<162.4 \text { hours) }\end{array}$ & 1.43 & 0.54 to 3.77 & 0.48 \\
\hline $\begin{array}{l}\text { Training exposure. } \\
\text { high (>1SD above } \\
\text { mean,>346.0 hours) }\end{array}$ & 0.58 & 0.13 to 2.72 & 0.49 \\
\hline
\end{tabular}

Match exposure, intermediate $($ mean \pm SD) 1

Match exposure, low $(<1$ SD below mean, $<3.9$ hours)

Match exposure, high ( $>1$ SD above mean, $>15$ hours)

\begin{tabular}{|c|c|c|c|}
\hline Univariate analysis & OR & $95 \% \mathrm{Cl}$ & $P$ value \\
\hline $\begin{array}{l}\text { Match and training } \\
\text { exposure, intermediate } \\
\text { (mean } \pm \text { SD) }\end{array}$ & 1 & & \\
\hline $\begin{array}{l}\text { Match and training } \\
\text { exposure, low }(<1 \mathrm{SD} \\
\text { below mean, }<169.6 \text { hours })\end{array}$ & 1.22 & 0.44 to 3.42 & 0.70 \\
\hline $\begin{array}{l}\text { Match and training } \\
\text { exposure. high }(>1 \text { SD } \\
\text { above mean, }>357.7 \text { hours) }\end{array}$ & 0.57 & 0.12 to 2.63 & 0.47 \\
\hline \multicolumn{4}{|c|}{ Continuous variables } \\
\hline Age (years) & 1.12 & 0.90 to 1.39 & 0.32 \\
\hline Height (cm) & 0.99 & 0.95 to 1.04 & 0.81 \\
\hline Weight (kg) & 1.00 & 0.96 to 1.04 & 0.98 \\
\hline $\mathrm{BMI}\left(\mathrm{kg} / \mathrm{m}^{2}\right)$ & 1.02 & 0.87 to 1.19 & 0.79 \\
\hline FPKPA $\left({ }^{\circ}\right)$ & 1.01 & 0.97 to 1.05 & 0.59 \\
\hline Training exposure (hour) & 1.00 & 0.99 to 1.00 & 0.35 \\
\hline Match exposure (hour) & 1.01 & 0.94 to 1.08 & 0.86 \\
\hline $\begin{array}{l}\text { Match and training } \\
\text { exposure (hour) }\end{array}$ & 1.00 & 0.99 to 1.00 & 0.36 \\
\hline
\end{tabular}

*Only one variable achieved $\mathrm{P}<0.20$; therefore, no multivariate analysis was performed.

BMI, body mass index; FPKPA, frontal plane knee projection angle.

risk is a result of improved knee control. It would be worthwhile to assess this by a randomised controlled trial with pretraining/post-training knee control measurements.

\section{Ankle injury risk factors}

Large FPKPA was associated with the risk of ankle injuries. It is known that ankle function contributes to knee valgus movement, but knee valgus has not previously been linked to ankle injuries. Mauntel et al found that subjects displaying valgus during the SLS had a limited dorsiflexion range of motion. ${ }^{15}$ They proposed that during the SLS, the limited dorsiflexion range of motion causes neuromuscular compensation, which is observed as hip adduction. However, this is not supported by the findings of Zeller et al. ${ }^{18}$ They compared the kinematics of men and women during the SLS and detected significantly more knee valgus, ankle dorsiflexion and ankle pronation in women. ${ }^{18}$ Our results indicate an association between frontal plane knee control and the risk of ankle injuries, but our data do not provide further insight to the role of ankle function on knee valgus.

\section{SLS test as a screening tool}

The ROC curve analyses indicate that the 2D analysis of the SLS test is not a suitable screening tool for lower extremity injuries or ankle injuries due to poor combined specificity and sensitivity. Bahr suggested that the main challenge with athletic screening tests is the overlap between the groups of injured and uninjured athletes. ${ }^{46}$ 


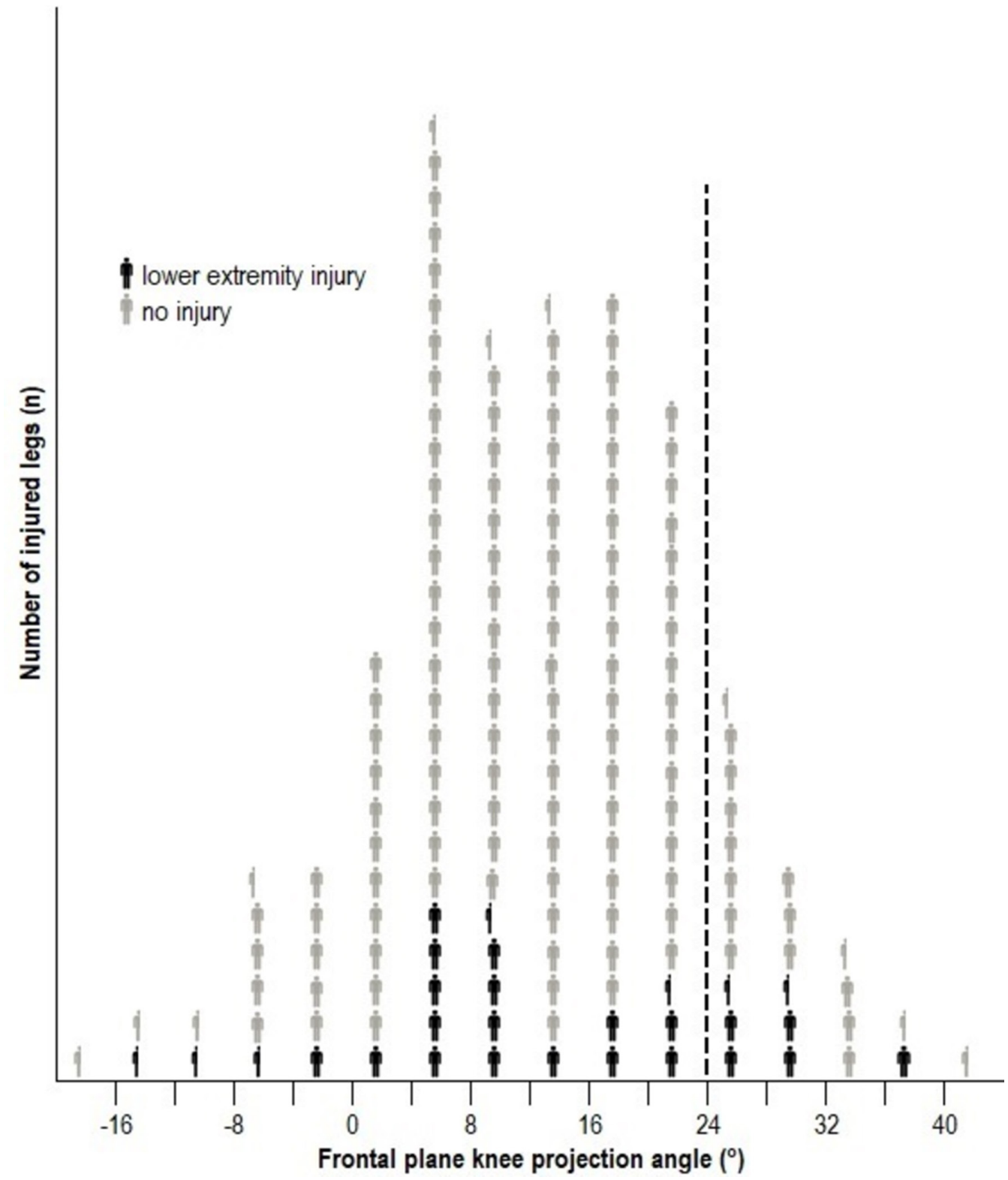

Figure 3 Representation of the distribution of injured and uninjured lower extremities by frontal plane knee projection angle. Each full icon represents two lower extremities, not necessary of the same athlete. The vertical line represents the cut-off point for the high frontal plane knee projection angle $\left(>23.8^{\circ}\right)$.

Bahr's conclusion is supported by our data, as illustrated in figure 3. The FPKPA fails to divide the athletes into two distinctive groups, which would be necessary for a screening tool. Our results demonstrate the SLS alone is not specific and sensitive enough to be used as a screening tool.

\section{Study strengths and weaknesses}

The size of the cohort can be viewed as a strength of the study: complete data were obtained from 306 athletes. In addition, the prospective nature of the injury collection and careful video assessment of the SLS test by a single researcher were study strengths.

However, our study has also some limitations. The purpose of this study was to analyse the predictive value of the FPKPA on future injuries, and therefore the analysis was performed on athletes who had been free from injury for 12 months prior to the study. Previous injuries were collected using a questionnaire with a 12-month recall period; therefore, recall bias could have influenced the prevalence of previous injuries. Additionally, the information on injured athletes was collected from the coaches. It is possible that the coaches were not aware of all minor injuries and this could have led to under-reporting. For this reason, we excluded all injuries that did not result in time-loss from the analyses.

During the study, 55 athletes did not complete the 12-month follow-up, making the drop-out rate $15 \%$. In most cases, the subject quit the sport. The decline in physical activity during adolescence is well documented. ${ }^{47}$ 
Therefore, we consider the drop-out rate in this study to be typical of the population.

\section{CONCLUSIONS}

This study provides further understanding of the role of knee control on injury risk. The findings demonstrate that a large FPKPA during the SLS test is associated with an elevated risk of lower extremity injuries. However, the results indicate that the FPKPA measured during the SLS test is not by itself a sufficient screening tool for the risk of future injuries.

Acknowledgements We would like to thank the athletes, coaches and contact persons of each participating team for their excellent cooperation. We are grateful to physiotherapist Irja Lahtinen for coordinating and conducting the baseline testing and to statistician Kari Tokola for his statistical advice.

Contributors All authors were involved in conceiving the study. All authors contributed to study concept and design. KP and AMR were responsible for conducting the data acquisition. AMR was responsible for the video analysis, data analysis and interpretation. AMR was the significant manuscript writer. KP, TK, TV, PK, AH, UMK, JA, JPe and JPa were significant manuscript revisers. All authors have approved the submitted version of the manuscript. AMR is the guarantor.

Funding This study was financially supported by the Finnish Ministry of Education and Culture, the Competitive State Research Financing of the Expert Responsibility Area of Tampere University Hospital (Grants 9N053, 9S047, 9T046), and the Foundation of Sports Institute (Urheiluopistosäätiö).

Competing interests None declared.

Patient consent Obtained.

Ethics approval The study was approved by the Ethics Committee of Pirkanmaa Hospital District (ETL code R10169).

Provenance and peer review Not commissioned; externally peer reviewed.

Open Access This is an Open Access article distributed in accordance with the Creative Commons Attribution Non Commercial (CC BY-NC 4.0) license, which permits others to distribute, remix, adapt, build upon this work non-commercially, and license their derivative works on different terms, provided the original work is properly cited and the use is non-commercial. See: http://creativecommons.org/ licenses/by-nc/4.0/

C Article author(s) (or their employer(s) unless otherwise stated in the text of the article) 2018. All rights reserved. No commercial use is permitted unless otherwise expressly granted.

\section{REFERENCES}

1. Agel J, Olson DE, Dick R, et al. Descriptive epidemiology of collegiate women's basketball injuries: National Collegiate Athletic Association Injury Surveillance System, 1988-1989 through 20032004. J Athl Train 2007:42:202-10.

2. Clausen MB, Zebis MK, Møller M, et al. High injury incidence in adolescent female soccer. Am J Sports Med 2014;42:2487-94.

3. Moller M, Attermann J, Myklebust G, et al. Injury risk in Danish youth and senior elite handball using a new SMS text messages approach. Br J Sports Med 2012;46:531-7.

4. Pasanen K, Parkkari J, Kannus P, et al. Injury risk in female floorball: a prospective one-season follow-up. Scand J Med Sci Sports 2008;18:49-54.

5. Söderman K, Adolphson J, Lorentzon R, et al. Injuries in adolescent female players in European football: a prospective study over one outdoor soccer season. Scand J Med Sci Sports 2001:11:299-304.

6. Åman M, Forssblad M, Henriksson-Larsén K. Incidence and severity of reported acute sports injuries in 35 sports using insurance registry data. Scand J Med Sci Sports 2016;26:451-62.

7. Le Gall F, Carling C, Reilly T. Injuries in young elite female soccer players: an 8-season prospective study. Am J Sports Med 2008;36:276-84.

8. Myer GD, Ford KR, Hewett TE. Rationale and clinical techniques for anterior cruciate ligament injury prevention among female athletes. J Athl Train 2004;39:352-64.
9. Read PJ, Oliver JL, De Ste Croix MB, et al. Neuromuscular risk factors for knee and ankle ligament injuries in male youth soccer players. Sports Med 2016;46:1059-66.

10. Hewett TE, Myer GD, Ford KR, et al. Biomechanical measures of neuromuscular control and valgus loading of the knee predict anterior cruciate ligament injury risk in female athletes: a prospective study. Am J Sports Med 2005;33:492-501.

11. Krosshaug T, Steffen K, Kristianslund E, et al. The vertical drop jump is a poor screening test for ACL injuries in female elite soccer and handball players: a prospective cohort study of 710 athletes. $A m ~ J$ Sports Med 2016;44:874-83.

12. Leppänen M, Pasanen K, Kujala UM, et al. Stiff landings are associated with increased $A C L$ injury risk in young female basketball and floorball players. Am J Sports Med 2017;45:386-93.

13. O'Kane JW, Tencer A, Neradilek M, et al. Is knee separation during a drop jump associated with lower extremity injury in adolescent female soccer players? Am J Sports Med 2016;44:318-23.

14. Crossley KM, Zhang WJ, Schache AG, et al. Performance on the single-leg squat task indicates hip abductor muscle function. $A m \mathrm{~J}$ Sports Med 2011;39:866-73.

15. Mauntel TC, Begalle RL, Cram TR, et al. The effects of lower extremity muscle activation and passive range of motion on single leg squat performance. J Strength Cond Res 2013;27:1813-23.

16. Mauntel TC, Frank BS, Begalle RL, et al. Kinematic differences between those with and without medial knee displacement during a single-leg squat. J Appl Biomech 2014;30:707-12.

17. Stensrud S, Myklebust G, Kristianslund E, et al. Correlation between two-dimensional video analysis and subjective assessment in evaluating knee control among elite female team handball players. Br J Sports Med 2011;45:589-95.

18. Zeller BL, McCrory JL, Kibler WB, et al. Differences in kinematics and electromyographic activity between men and women during the single-legged squat. Am J Sports Med 2003;31:449-56.

19. McLean SG, Walker K, Ford KR, et al. Evaluation of a two dimensional analysis method as a screening and evaluation tool for anterior cruciate ligament injury. Br J Sports Med 2005;39:355-62.

20. Munro A, Herrington L, Carolan M. Reliability of 2-dimensional video assessment of frontal-plane dynamic knee valgus during common athletic screening tasks. J Sport Rehabil 2012;21:7-11.

21. Pasanen K, Rossi MT, Parkkari J, et al. Predictors of lower extremity injuries in team sports (PROFITS-study): a study protocol. BMJ Open Sport Exerc Med 2015;1:e000076.

22. Räisänen A, Pasanen $\mathrm{K}$, Krosshaug $\mathrm{T}$, et al. Single-leg squat as a tool to evaluate young athletes' frontal plane knee control. Clin J Sport Med 2016;26:478-82.

23. Bahr R, Holme I. Risk factors for sports injuries-a methodological approach. Br J Sports Med 2003;37:384-92.

24. Hosmer DW, Lemeshow S, Sturdivant RX. Applied logistic regression. 3rd Edn Electronic book: John Wiley \& Sons, Incorporated, 2013:177.

25. Willson JD, Ireland ML, Davis I. Core strength and lower extremity alignment during single leg squats. Med Sci Sports Exerc 2006;38:945-52.

26. Myer GD, Ford KR, Brent JL, et al. Differential neuromuscular training effects on ACL injury risk factors in 'high-risk' versus 'lowrisk' athletes. BMC Musculoskelet Disord 2007;8:39.

27. Claiborne TL, Armstrong CW, Gandhi V, et al. Relationship between hip and knee strength and knee valgus during a single leg squat. J Appl Biomech 2006;22:41-50.

28. Stickler L, Finley M, Gulgin H. Relationship between hip and core strength and frontal plane alignment during a single leg squat. Phys Ther Sport 2015;16:66-71.

29. Chappell JD, Limpisvasti O. Effect of a neuromuscular training program on the kinetics and kinematics of jumping tasks. $A m \mathrm{~J}$ Sports Med 2008;36:1081-6.

30. Kato S, Urabe Y, Kawamura K. Alignment control exercise changes lower extremity movement during stop movements in female basketball players. Knee 2008;15:299-304.

31. Lim BO, Lee YS, Kim JG, et al. Effects of sports injury prevention training on the biomechanical risk factors of anterior cruciate ligament injury in high school female basketball players. Am J Sports Med 2009;37:1728-34.

32. Myer GD, Ford KR, McLean SG, et al. The effects of plyometric versus dynamic stabilization and balance training on lower extremity biomechanics. Am J Sports Med 2006;34:445-55.

33. Myer GD, Ford KR, Palumbo JP, et al. Neuromuscular training improves performance and lower-extremity biomechanics in female athletes. J Strength Cond Res 2005;19:51-60.

34. Noyes FR, Barber-Westin SD, Fleckenstein C, et al. The drop-jump screening test: difference in lower limb control by gender and effect 
of neuromuscular training in female athletes. Am J Sports Med 2005;33:197-207.

35. Emery CA, Meeuwisse WH. The effectiveness of a neuromuscular prevention strategy to reduce injuries in youth soccer: a clusterrandomised controlled trial. Br J Sports Med 2010;44:555-62.

36. Emery CA, Roy TO, Whittaker JL, et al. Neuromuscular training injury prevention strategies in youth sport: a systematic review and metaanalysis. Br J Sports Med 2015;49:865-70.

37. Hewett TE, Lindenfeld TN, Riccobene JV, et al. The effect of neuromuscular training on the incidence of knee injury in female athletes. A prospective study. Am J Sports Med 1999;27:699-706.

38. Hübscher M, Zech A, Pfeiffer K, et al. Neuromuscular training for sports injury prevention: a systematic review. Med Sci Sport Exerc 2010;42:413-21.

39. Hägglund M, Atroshi I, Wagner P, et al. Superior compliance with a neuromuscular training programme is associated with fewer $\mathrm{ACL}$ injuries and fewer acute knee injuries in female adolescent football players: secondary analysis of an RCT. Br J Sports Med 2013;47:974-9.

40. Junge $A$, Rösch D, Peterson L, et al. Prevention of soccer injuries: a prospective intervention study in youth amateur players. $\mathrm{Am} \mathrm{J}$ Sports Med 2002;30:652-9.

41. Longo UG, Loppini M, Berton A, et al. The FIFA 11+ program is effective in preventing injuries in elite male basketbal players: a cluster randomized controlled trial. Am J Sports Med 2012;40:996-1005.

42. Mandelbaum BR, Silvers HJ, Watanabe DS, et al. Effectiveness of a neuromuscular and proprioceptive training program in preventing anterior cruciate ligament injuries in female athletes: 2-year followup. Am J Sports Med 2005;33:1003-10.

43. Marshall DA, Lopatina E, Lacny S, et al. Economic impact study: neuromuscular training reduces the burden of injuries and costs compared to standard warm-up in youth soccer. Br J Sports Med 2016:50:1388-93.

44. Olsen OE, Myklebust G, Engebretsen L, et al. Exercises to prevent lower limb injuries in youth sports: cluster randomised controlled trial. BMJ 2005;330:449.

45. Rössler R, Donath L, Verhagen E, et al. Exercise-based injury prevention in child and adolescent sport: a systematic review and meta-analysis. Sports Med 2014;44:1733-48.

46. Bahr R. Why screening tests to predict injury do not workand probably never will...: a critical review.. Br J Sports Med 2016:bjsports - 2016-096256.

47. Dumith SC, Gigante DP, Domingues MR, et al. Physical activity change during adolescence: a systematic review and a pooled analysis. Int J Epidemiol 2011;40:685-98. 